\title{
Música, tecnologia e educação musical: a guitarra em foco
}

\section{Alexsander Vanzela, Leida Calegário de Oliveira, Marivaldo Aparecido de Carvalho}

Resumo: A música é algo presente na vida da pessoas e sua divulgação feita através de vários meios, iniciou-se com discos (os chamados bolachões), fitas k-7, CD's e atualmente em diversas mídias, faz com que o registro musical seja algo perpétuo. Nesse cenário musical, a guitarra elétrica é um instrumento que se destaca principalmente em bandas de rock'n roll e que possui amantes no mundo todo. $O$ fato da guitarra elétrica ser um instrumento que chama a atenção, faz com que muitos indivíduos ingressem de alguma forma no estudo musical, se identificando nos mais variados estilos e buscando se igualar a seus ídolos musicais. Em meio a busca do saber musical, a sociedade disponibiliza ao indivíduo escolas de música, professores particulares e a internet como meios de propagação do ensino musical e de outros. Nesses estudos é comum verificar músicos passando técnicas do instrumento musical a qual procura o aprimoramento, teoria musical que nem sempre existe uma didática pelo fato que as matérias são vistas de forma ampla, podendo o indivíduo que busca o aprendizado, se perder a tantas informações lançadas na rede. A internet modificou radicalmente a vida da população mundial, após a segunda guerra o mundo teve acesso a inúmeras informações, serviços e vários profissionais, inclusive os músicos, utilizam deste mecanismo para sua divulgação. A educação musical utiliza como facilitador os meios tecnológicos para auxiliar o aprendiz em seus estudos, sejam eles teóricos ou práticos, tentando tornar as aulas de teoria musical mais agradáveis.

Abstract: Music is something present in the lives of people and their
disclosure made through various means, started with disks (called
bolachões), ribbons k-7, CD's and currently in various media, makes the
musical record is something perpetual. In this music scene, the electric
guitar is an instrument that stands out mainly in rock and roll bands and has
lovers worldwide. The fact that the electric guitar is an instrument that draws
attention, causes many individuals from entering somehow in the music
study, identifying the most varied styles and seeking to emulate their music
idols. Amid the pursuit of musical knowledge, the company provides to the 
individual music schools, private teachers and the Internet as a means of spreading musical education and others. In these studies it is common to see musicians passing techniques musical instrument which seeks to improve, music theory that there is not always a didactic by the fact that the materials are broadly seen, allowing the individual seeking learning, if you lose so much information released on the network. The Internet has radically changed the life of the world's population after the Second World War the world had access to lots of information, services and various professionals, including musicians, use this mechanism for disclosure. Music education as a facilitator uses technological means to assist the student in their studies, whether theoretical or practical, trying to make the most enjoyable music theory classes.

\section{Música, tecnologia e educação musical}

Falar sobre tecnologia, música, educação musical e a utilização de softwares como elementos de aprendizagem, requer que seja lembrado o início da era da informática. A segunda guerra mundial, que foi marcada por vários acontecimentos trágicos, também impulsionou o desenvolvimento dos computadores para o processamento de cálculos matemáticos, destinados aos problemas de balística e decifração de códigos criptográficos (CARVALHO, 2006, p. 6). Sob esse impulso, houve um avanço na tecnologia e a criação da Internet, inventada em 1969 com o nome de ARPAnet (rede da Advanced Research Projects Agency). A ARPAnet foi utilizada primeiramente no departamento de defesa dos EUA e posteriormente houve sua liberação para uso comercial em 1987. Em 1992, esse foi o meio de comunicação mais disseminado mundialmente, com o surgimento da web, e em 1995 a "rede" foi liberada no Brasil (TATIT, 2003). Hoje é amplamente utilizada, como se sabe, com muita frequência para estudos e aulas, e, claro, como meio de entretenimento.

$\mathrm{O}$ avanço tecnológico que deu origem à informática e seus programas, à Internet e à enxurrada de novas linguagens que invadiram a música e a cultura geral, começou, entretanto, em um momento bastante anterior e em outro contexto: o da Pré-história. Existem 
vestígios de instrumentos tão antigos como a possível flauta Neanderthal de fêmur de urso, descoberta na Eslovênia e datada de 50.000 anos atrás no período Paleolítico, ou antigas flautas chinesas de ossos de pássaros, datadas do período Neolítico, entre 7.000 e 5.700 aC (McDERMOTT; HAUSER, 2005). A existência desses vestígios nos mostra a relação estreita entre o homem e a música.

A partir daquele instante começava a saga de aprimoramento dos instrumentos, e percebemos o primeiro efeito real de uma tecnologia mais refinada no aperfeiçoamento dos mesmos, através da melhoria técnica dos luthiers - nome dado aos fabricantes artesanais de instrumentos - que desenvolviam trabalhos na madeira para chegar a resultados sonoros mais satisfatórios. Antonio Stradivari ${ }^{1}$ (1644-1737) é considerado o expoente máximo desta arte. (GOHN, 2001, p. 2).

A descoberta da eletricidade e dos meios de produzi-la não foi menos importante para a música. O uso da eletricidade foi aplicado para o desenvolvimento do aparelho que permitiu o primeiro registro do som, o fonógrafo por Thomas Edison, em 1877. Esse armazenava e reproduzia tudo o que se relacionava à sonoridade (WAIZBOARD, 2014).

O fonógrafo (fonos-graphos: escrita do som) é um aparelho mecânico que se presta tanto à gravação como à reprodução de sons. Na situação de gravação, os sons emitidos, em geral captados por um cone acústico, vibram uma membrana, por sua vez ligada a uma agulha que, acompanhando os movimentos da membrana, sulca uma folha de estanho que recobre um cilindro em rotação, deixando registrado assim, nos sulcos sobre a folha de estanho, uma trilha sonora helicoidal. A membrana (ou diafragma), vibrando em função das sonoridades recebidas, transforma os sons em oscilações mecânicas, repassadas à agulha e, desta, à folha de estanho. Na situação de reprodução, o processo é o mesmo, mas em sentido inverso. $O$ cilindro recoberto de estanho é posto a girar

\footnotetext{
${ }^{1} \mathrm{O}$ italiano Antonio Giacomo Stradivari.
} 
em sentido contrário, oscilando a agulha e, assim, a membrana, que produz as oscilações sonoras ampliadas na campana. Inicialmente, a rotação do cilindro resultava do giro de uma manivela, e a velocidade de rotação vinha do controle da velocidade com que a manivela era movida. (WAIZBOARD, 2014).

Desde a invenção do fonógrafo, passando pelo grafofone de Graham Bell em 1886, até o gramofone, inventado pelo alemão Émile Berliner em 1888 para o registro do som em discos metálicos, os avanços pela possibilidade de registro do som tiveram não poucos impactos. O gramofone permitia a reprodução de cópias a partir de uma gravação primeira, ou seja, foi a invenção da cópia master (GOHN, 2001).

No Brasil, a indústria fonográfica teve seu início em 1894 em Porto Alegre e, a partir daí, expandiu-se. Em 1904, os brasileiros conheceram o gramofone, que mais tarde seria chamado de toca discos. Já no ano de 1948, apareceram os discos "inquebráveis" e muitas gravadoras independentes. Na década de 1960 e 1970 houve uma explosão de consumo de eletrodomésticos como rádio, vitrola e TV (DELMIRO, 2001).

Instrumentos tradicionais elétricos foram desenvolvidos, como o violão elétrico, a guitarra elétrica, contrabaixos, teclados, violinos e uma série de outros mais. A guitarra foi eletrificada em 1941 pelo guitarrista Les Paul e ficou conhecida como Tora. O modelo Les Paul da marca Gibson $^{\circledR}$, atualmente conhecido, entretanto, foi construído por Paul Gbisby em 1948. A história da Fender $^{\circledR}$, famosa marca de guitarras, preferência de muitos guitarristas, foi iniciada em 1946 por Clarence Leonidas Fender, resultando no lançamento da primeira guitarra de corpo sólido em 1949 com o nome Squire (MACHADO, 2009). A guitarra é comumente comparada ao violão, mas possui sistema de escala que chega a ter 27 trastes ou até mais, que permite um agudo extremo não possível no violão. O formato da guitarra proporciona um alcance de notas mais agudas, superiores às do violão, sendo que a cavidade do 
corpo da guitarra próxima ao braço, chamada de cutaway, é a responsável pelo acesso às casas mais agudas (MACHADO, 2009).

O som dos instrumentos acústicos e da própria voz, com a invenção dos captadores, microfones e amplificadores também passou a ter maior alcance, mudando a dinâmica das apresentações dirigidas a pequenas audiências para os mega shows e festivais, transmitidos pela televisão, rádio e pela internet. O contexto cultural atual foi analisado por Herschmann; Kischinhevsky (2008) do ponto de vista da "espetacularização da sociedade contemporânea" sem, entretanto, atribuição de significado pejorativo:

O espetáculo é um traço característico da sociedade contemporânea, mas não necessariamente reflete aspectos negativos a serem extirpados do social, vindo a se constituir numa ameaça à 'razão' - ainda que a crise dos 'projetos coletivos' e das noções iluministas seja mais do que evidente." "o espetáculo deve sempre ser analisado criticamente, mas pode ser agenciado por diferentes atores sociais e organizações, podendo estar a serviço da normatização social ou da construção de uma perspectiva ou de ações críticas que coloquem em pauta, por exemplo, reivindicações de diferentes grupos sociais. (HERSCHMANN; KISCHINHEVSKY, 2008, p. 102).

Muito da espetacularização que Herschmann e Kischinhevisky (2008) analisam é proveniente da democratização do acesso à informação e à tecnologia, de forma maciça, provida ou não de análise. Nas palavras desses autores, a espetacularização re-encanta o drama contemporâneo à sua maneira, mas é fato que novas vozes se fazem ouvir, cantam seu cotidiano e suas questões, protagonizando o espetáculo atual. Com o desenvolvimento de novos equipamentos e aperfeiçoamento dos instrumentos, diversas mudanças aconteceram na cultura musical: tornando-se possível o registro do som, deixa de ser obrigatória a notação para preservar a memória musical - embora o 
registro para preservação da autoria ainda seja necessário - a leitura da partitura deixou de ser imprescindível para o desenvolvimento da arte de tocar, a produção e disseminação musical em massa mesclaram valores culturais, os novos programas populares de gravação e o uso do computador democratizaram o acesso à música e permitiram possibilidades de experimentação por profissionais, amadores e até por aqueles com pouquíssimo conhecimento musical. Gêneros musicais tradicionais foram reinventados e mesclados, novos gêneros foram criados ou disseminados até um ponto anteriormente impensável, como o rock, o rap, o funk, o hip hop, o fusion, a música eletrônica e outros, numa miscigenação de ritmos e estilos à altura da formação étnica da população brasileira, embora o fenômeno seja mundial.

A procura por cursos de música aumentou, principalmente em relação aos instrumentos usados por bandas famosas popularizadas pela TV, dentre esses a guitarra, o baixo e a bateria. O filme "The Blackboard Jungle" (1955) fez um "abre-alas" para o rock'n roll, com a trilha sonora "Rock around the clock' que deixou os jovens alucinados pelo estilo (PIRES; BÄR, 2013). Na década de 60, artistas como Jimi Hendrix consagraram o uso da guitarra em suas performances e com seu talento. O som distorcido do rock atual foi sua marca sonora e inspirou toda uma geração de guitarristas. Na mesma época, Eric Clapton se tornou um ícone usando o mesmo estilo de guitarra, o modelo Stratocaster. Outros guitarristas de destaque no rock surgiriam mais tarde, como Brian May, Jimmy Page e Ritchie Blackmore, na década de 70, Van Hallen, Steve Vai, Joe Satriani e os brasileiros Wander Taffo, Edu Ardanuy, Kiko Loureiro e muitos mais que despontaram na década de 80 .

Após o ingresso do rock'n rol/ no Brasil, diversos estilos baseados no rock foram surgindo, como punk e o rock nacional, chamado de BRock. Os ritmos "barulhentos" atraíam os jovens e os impulsionavam a criar uma identidade, através da atitude e das roupas que permitiam perceber a que turma pertenciam. As turmas punks de São Paulo e do Rio de Janeiro da década de 80 eram compostas predominantemente por 
metalúrgicos e utilizavam jaquetas militares, coturnos e cortes de cabelo agressivo. Os roqueiros (BRockers) da época não tinham um vestuário tão marcante, apenas a preferência por roupas pretas. Bandas como Ultraje a Rigor, Ira!, Camisa de Vênus, Plebe Rude e Legião Urbana fizeram músicas em tom contestador ou irônico que atraíam os jovens (ROCHEDO, 2011). Muitas bandas da época misturavam elementos do punk ao rock e utilizavam a guitarra como instrumento principal.

O desenvolvimento dos equipamentos, dos instrumentos, da informática e, mais tarde, da Internet propôs ao mundo uma nova linguagem, um novo estilo. As palavras em inglês tornaram-se cada vez mais comuns no cotidiano e foram tomando seu espaço, especialmente entre e através dos membros da comunidade dos internautas. Aliás, novas palavras surgiram também no português para acomodar a linguagem específica necessária a esse novo meio e gradualmente atingiram diversas áreas do saber, incluindo a música. Palavras como display, on, off, play (GOHN, 2001) entre outras, fazem parte do contexto de educação musical, não devido apenas ao surgimento da internet. Equipamentos de áudio e vídeo e instrumentos modernos usam essas palavras em sua estrutura e nos manuais. Palavras estrangeiras dão nome a técnicas de guitarra e estão incluídas nos estudos, escrita e leitura como palm mute (abafar as cordas com a mão da palheta), bend (subir $1 / 2,1$ ou mais tons), hammer on (ligado ascendente), pull off (ligado descendente), cujo significado desafia uma tradução prática.

Os recursos se ampliaram e a linguagem acompanhou a mudança. Se o homem primitivo chegou a diferentes notas com suas vocalizações e reconhecendo os sons característicos de cada mensagem com os recursos de que dispunha (GOHN, 2001), na era tecnológica o homem utiliza os meios disponíveis para o aumento de possibilidades de estudo, criação e informação musical: 
Apesar do computador digital não ter surgido originalmente como um instrumento musical, sua versatilidade e alta capacidade de simulação, em tempo real, permitem tal uso. Além disso, diversos programas e equipamentos foram feitos para transformá-lo em um complexo sistema interativo de criação e performance, e sua presença não apenas é constante em concertos de música experimental como também as influências de seu uso nas atividades musicais são profundas e merecem atenção. (MISKALO, 20[?], p. 282).

Hoje, o internauta se cadastra num endereço eletrônico, instala programas agregadores e de leitura, escrita e gravação em arquivos digitais com muita facilidade, alguns dos quais podem ser baixados gratuitamente via internet (HERSCHMANN; KISCHINHEVSKY, 2008). O programa Guitar Pro 6, por exemplo, possui uma versão Demo, utilizável por 30 dias. Todos esses recursos, novas possibilidades e experimentações confrontaram o novo e o clássico, inevitavelmente. Esse conflito repercute nos discursos sobre o mérito do que é a música de boa ou má qualidade, muitas vezes contrastando a música popular, a música produzida pelas camadas sociais mais pobres e pelas variadas culturas, com a música dos colonizadores europeus, a música erudita ou clássica. Não se trata aqui de ignorar que a qualidade estética é importante para uma obra de arte, incluindo as musicais. Tampouco negamos que estamos expostos, às vezes submetidos, a todo tipo de experimentação musical, muitas delas trazendo pouco valor artístico. Entretanto, a análise estética de uma obra de arte não pode ser feita simplesmente segundo o padrão historicamente adotado pela cultura dominante. $\mathrm{O}$ impacto desse confronto atingiu a educação musical em muitas escolas tradicionais de música, inclusive no que se refere ao método de ensino, pela resistência de adotar novas linguagens e recursos. Paulatinamente, essa resistência vem sendo vencida, mas não sem causar muitas dificuldades para os professores e estudantes de instrumentos modernos. 
Paulo Freire nos diz que "não pode existir uma teoria pedagógica, que implica fins e meios da ação educativa, que esteja isenta de um conceito de homem e mundo" (FREIRE, 1994, p. 9). Tendo como foco a análise sobre música, mundo e natureza, que tecemos anteriormente, e considerando que a música é um construto humano sócio-histórico imbuída de sentido, e que o sentido se dá a partir da compreensão da linguagem, também o ensino musical precisa ser contextualizado, considerando os indivíduos de hoje imersos na modernização e na disseminação de tecnologia. No mundo em que vivemos, não é possível excluir as ferramentas tecnológicas do processo pedagógico da música, uma vez que estas se tornaram tão usuais e acessíveis. Se a música no cotidiano está permeada de tecnologia, faria sentido uma aula sem a linguagem tecnológica que atrai tantos aprendizes para os cursos de guitarra, baixo, teclado? Estaríamos limitando as possibilidades criativas e pedagógicas apenas para manter uma prática convencional.

A questão não tem como foco a retirada da notação tradicional dos métodos de ensino. Recomendar que o uso da partitura fosse excluído de toda forma de educação musical, equivaleria a dizer que não se deve mais aprender a escrita manual por ser possível digitar um texto. Se abolíssemos o ensino da letra cursiva, com o tempo, textos manuscritos da nossa cultura se tornariam tão indecifráveis quanto as escritas antigas que hoje exigem a interpretação de especialistas. $O$ mesmo é valido para a partitura. É uma linguagem universal que permite o registro de uma obra musical e sua interpretação, independentemente da gravação do som, exigindo apenas um intérprete habilitado: um conhecimento que não deve ser perdido. Escrever e interpretar a notação por partitura e por tablatura são habilidades complementares. Trata-se de saber combinar diferentes linguagens e recursos para o aprendizado de instrumentos que requerem uma aproximação do novo.

A guitarra elétrica tem este foco. É um instrumento contemporâneo, que atrai pela sonoridade, pela textura que imprime ao 
som, pelas bandas de rock e até pelos jogos eletrônicos como o Guitar Heroes (MACHADO, 2009). Assim, quem se dispõe a aprender a tocar guitarra traz uma linguagem própria, adquirida em um contexto que não pode ser ignorado para que o processo pedagógico seja efetivo. $O$ ensino da guitarra é feito de múltiplas formas: por meio de instruções orais, por meio de imitações ou de forma mais complexa como nos institutos e conservatórios de música. Há aqueles que advogam em favor de um aprendizado mais livre.

Sendo a guitarra um instrumento cujo aprendizado se dá, na maioria das vezes, de forma aural e por meio de imitações, é válida a ênfase na oralidade e a utilização de linguagens alternativas, tais como cifras e tablaturas, as quais conduzam os alunos principiantes a uma prática musical de fácil acesso, inicialmente baseada em restritas informações teóricas e maior estímulo à criatividade. (FERREIRA, 2010).

A teoria pode-se dizer que é o "procedimento ou conjunto de procedimentos que tem como objetivo um determinado resultado" (RIBEIRO, 2011). Um ensino de música sem conhecimentos teóricos é limitado, semelhante aos desenvolvidos por pessoas que são capazes de tocar uma música, de ouvido, sem, entretanto, se dar conta daquilo que executa, no sentido teórico, pois é fato musical que muitos "tocadores de ouvido", são capazes de performances musicais perfeitas, mas nesse momento estamos focando o processo de ensino e aprendizagem musical. "O aprendizado musical seria a síntese ou produto das condutas receptivo-expressivas que envolvem o processo de musicalização" (GAINZA, 1988, p. 33). Para o músico, em algum momento, será necessário escrever ou registrar de alguma maneira um determinado exercício ou composição, um conhecimento que foge da simples imitação. É desejável, portanto, que o estudante aprenda não apenas a imitar um som registrado, mas também a executar a partir da notação 
escrita, bem como a registrar suas próprias composições ou exercícios. Os recursos principais utilizados para o aprendizado de guitarra são partitura, tablatura, cifras e shapes (desenhos) além de alguns sinais diferentes, uma gama de possibilidades que disponibiliza ao aprendiz formas variadas para a captação do conteúdo. Essa variedade possibilita que o professor indique o caminho e que o aluno construa sua "própria música", desenvolvendo sua performance, "através do estímulo e de procedimentos metodológicos, para a execução em diferente estilos musicais" (FERREIRA, 2010).

Assumindo que o aprendizado da teoria musical é importante e tendo em mente que a maioria dos estudantes apontam para a dificuldade das aulas de percepção, bem como seu desinteresse pelas mesmas, a utilização de recursos facilitadores é extremamente importante. Nesse sentido, entendemos que para aproximar a linguagem das partituras de uma prática musical moderna, mais atraente e com nova roupagem, os programas de tecnologia da informação podem tornar o caminho mais fácil para a nova geração de aprendizes.

\section{Conclusão}

Utilizar um artifício facilitador no ensino musical, faz com que os aprendizes tenham como resultado final a rapidez no que é passado, distante daqueles que acreditam em que deve-se utilizar os mesmos mecanismos de ensino de tempos passados.

Hoje com a tecnologia da informação, é possível utilizar de softwares dedicados ao ensino musical, sendo um meio facilitador e atrativo pelos jovens, melhorando seu desempenho e proporcionando um estudo mais substancial, não que aqueles que não dispõe de um professor não possam aprender, mas se houver a possibilidade de ter 
um professor indicando o caminho, explicando e sanando as dúvidas, a melhora e a fluidez musical poderá ser de maior eficácia.

\section{Referências Bibliográficas}

CARVALHO, M.S.R.M.: A Trajetória da Internet no Brasil: Do surgimento das redes de computadores à Instituição dos mecanismos de Governança. Dissertação, Rio de Janeiro, $2006 \hat{~}$.

DELMIRO, E.S.: Origem e Desenvolvimento da indústria fonográfica no Brasil. XXIC Congresso Brasileiro de Comunicação, Campo Grande, MS, setembro de 2001 .

GAINZA, Violeta $H$. de: Estudos de Psicopedagogia Musical. Summus Editorial Ltda, vol. 31. São Paulo, 1988.

GOHN, D.M.: A Tecnologia da Música. XXIV Congresso Brasileiro da Comunicação, Campo Grande - MS, setembro 2001.

FERREIRA, S.: Ensino coletivo de guitarra: reflexão e ação pedagógica para a comunidade; uma proposta de método. Musifal, 2010. disponível em < http:// www.revista.ufal.br/musifal/Ensino\%20coletivo.pdf $>$ acesso em 16/04/2016.

FREIRE, Paulo: O Comunitário. Ed. 38, março de 1994, Ano VI Campinas, SP.

HERSCHMANN, M.; KISCHINHEVSKY, M.: A "geração podcasting" e os novos sos do rádio na sociedade do espetáculo e do entretenimento. Revista FAMECOS, Porto Alegre, n.37, dezembro de 2008.

MCDERMOTT, J.; HAUSER, M.: The originis of Music:Innateness, Uniqueness, and Evolution. Music Perception, volume 23, Issue I, pp. 2959, ISSN 0730-7829. University of california, 2005.

MISKALO, V.K.: O computador enquanto sistema instrumental musical de criação e performance na música interativa de concerto. IV Seminário Música Ciência Tecnologia: Fronteirtas e Rupturas. p. 281-288. [20-?]

PIRES, E.A.C.; BÄR, M.V.: Breve histórico do rock nacional: Entre letras e ideais, um instrumento de protesto político. I Congresso Internacional dos Estudos do Rock. Cascavél - PR, 2013.

RIBEIRO, H.L.: O estudo da técnica da guitarra elétrica. Apostila de Estudos. Maio de 2011, disponível em: < 
http:// docplayer.com.br/8879374-Hugo-leonardo-ribeiro-o-estudoda-tecnica-da-guitarra-eletrica.html >

ROCHEDO, A.C.: "Os filhos da revolução" A juventude urbana e o rock brasileiro dos anos 1980. Universidade Federal Fluminense. Niterói, 2011.

TATIT, L.: Ilusão enunciativa na canção. Per Musi.- Revista acadêmica de Música. Belo Horizonte. N. 29, 2014, p. 33-38

WAIZBOARD, L.: Fonógrafo. Novos Estudos 99, p. 27-46, julho 2014. 